\title{
2,3-Dibutoxynaphthalene-based tetralactam macrocycles for recognizing precious metal chloride complexes
}

\author{
Li-Li Wang, Yi-Kuan Tu, Huan Yao and Wei Jiang*
}

\author{
Full Research Paper \\ Address: \\ Shenzhen Grubbs Institute and Department of Chemistry, Southern \\ University of Science and Technology, Xueyuan Boulevard 1088, \\ Shenzhen 518055, China \\ Email: \\ Wei Jiang ${ }^{\star}$ - jiangw@sustech.edu.cn \\ ${ }^{*}$ Corresponding author \\ Keywords: \\ host-guest chemistry; macrocycles; molecular recognition; precious \\ metal chloride complexes
}

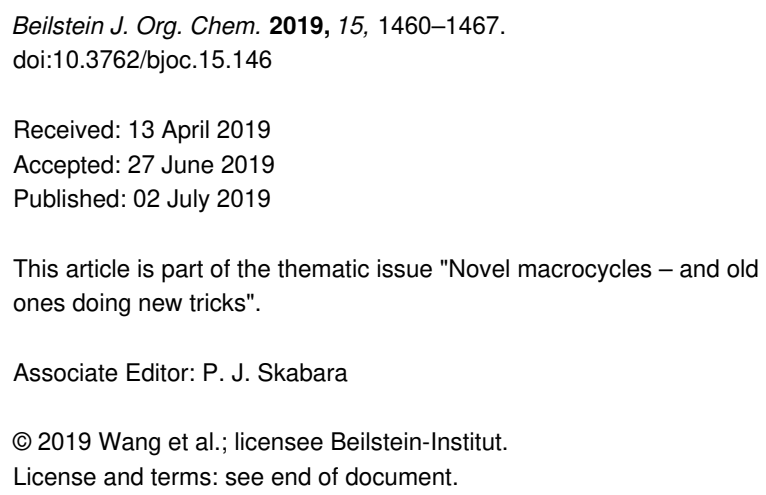

\begin{abstract}
Two new tetralactam macrocycles with 2,3-dibutoxynaphthalene groups as sidewalls have been synthesized and characterized. The macrocycle containing isophthalamide bridges can bind square-planar chloride coordination complexes of gold(III), platinum(II), and palladium(II) in $\mathrm{CDCl}_{3}$, while the macrocycle with 2,6-pyridine dicarboxamide bridging units cannot. This may be due to the shrunken cavity caused by intramolecular hydrogen bonds in the latter tetralactam macrocycle. The binding of the isophthalamidebased macrocycle is mainly driven by hydrogen bonds and electrostatic interactions. This naphthalene-based macrocycle has similar binding affinities to all the three abovementioned precious metal chloride complexes. This is in contrast to the fact that the tetralactam macrocycle with anthracene as the sidewalls only show good binding affinities to $\mathrm{AuCl}_{4}{ }^{-}$. The superior binding to all three complexes may be due to the conformational diversity of the naphthalene-based macrocycle, which make it conformationally adaptive to maximize the binding affinities. In addition, the macrocycle shows fluorescent quenching when adding the chloride metal complexes in its solution and may be used as a fluorescent sensor for the detection of these coordination complexes.
\end{abstract}

\section{Introduction}

Macrocyclic receptors are the major workhorses in supramolecular chemistry. Design and synthesis of new macrocyclic receptors with new properties is always attractive but is also challenging [1]. Tetralactam macrocycles with four amide $\mathrm{NH}$ residues have been studied for ca. three decades and used in a wide range of fields including molecular recognition, optical sensing, molecular machine etc. [2-13]. The amide $\mathrm{N}-\mathrm{H}$ groups directed into the cavity could form hydrogen bonds with guests, constituting the main driving forces for molecular recognition. This class of macrocycles, in particular the ones with single arene as sidewalls, have found wide applications in diverse fields: Leigh and co-workers reported many interlocked structures and molecular machines with tetralactam macrocycles [14-16]. The Smith group has used tetralactam macrocycles to 
encapsulate and stabilize deep-red fluorescent squaraine dyes for biomedical applications [17-20]. By introducing watersoluble groups to tetralactam macrocycles, Davis and co-workers realized selective recognition of glucose in water [21-23]. However, the aromatic sidewalls of these tetralactams are currently limited to benzene, anthracene and their derivatives (Scheme 1). The extension of the sidewalls to naphthalenes should be an important supplement to the previous works, and may even lead to interesting new binding properties.

During the last six years, our group have developed a series of naphthol-based macrocyclic receptors [24-29]. Of them, oxatub[4]arene [30,31] and zorb[4]arene [32,33] show multiple conformations due to the flipping of naphthalenes and thus resulted in a rather wide guest scope. Therefore, we wondered whether multiple conformations would be observed by incorpo- rating the 2,3-dialkoxynaphthalene units into tetralactam macrocycles as the sidewalls. How would this affect their binding affinity and selectivity of the resulting macrocycles?

Herein, we describe a pair of new tetralactam macrocycles with 2,3-dibutoxynaphthalene as the sidewalls. The tetralactam macrocycle with 2,6-pyridine dicarboxamide cannot bind square-planar chloride coordination complexes of gold(III), platinum(II), and palladium(II) in $\mathrm{CDCl}_{3}$, while the macrocycle containing isophthalamide bridging units bind these complexes with decent binding affinities. This macrocycle shows similar binding affinity to chloride, weaker affinity to the chloride complex of gold(III), and much stronger affinities to the chloride complexes of platinum(II) and palladium(II), when compared to the tetralactam macrocycle with anthracene sidewalls [34]. The difference in binding affinities and selectivity may be partially

previous work

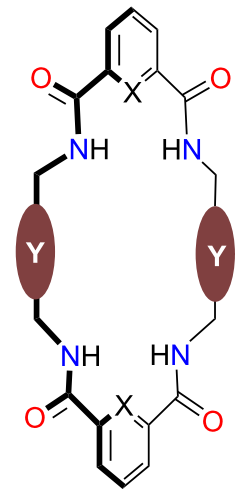<smiles>[Y]=C[OH2+]</smiles><smiles>Cc1c(C)c(C)c(C)c(C)c1C</smiles><smiles>COc1c(C)c(OC)c(OC)c(OC)c1C</smiles><smiles>Nc1c2ccccc2c(N)c2ccccc12</smiles><smiles>COc1cc2c(C)c3cc(OC)c(OC)cc3c(C#N)c2cc1OC</smiles>

this work

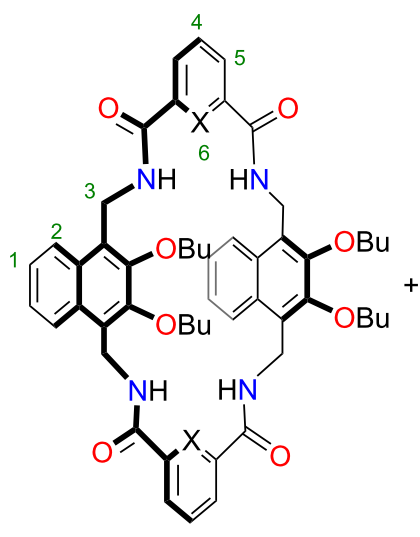

conformer I<smiles>[Y][Y4](=N)N</smiles>

s2

Scheme 1: (a) Chemical structures of the reported tetralactam macrocycles with aromatic sidewalls; (b) synthetic procedure to 2,3-dibutoxynaphthalene-based tetralactam macrocycles. Numberings on the structures are used for the proton assignment in the NMR spectra, and the protons are designated as $\mathrm{H} 1, \mathrm{H} 2$, and so on. 
due to the conformational diversity in the tetralactam macrocycles with 2,3-dibutoxynaphthalene as the sidewalls. Moreover, they are fluorescent and could in principle be used as a fluorescent sensor to these precious metal chloride complexes.

\section{Results and Discussion}

Synthetic procedures for the preparation of macrocycles $\mathbf{1}$ and $\mathbf{2}$ are shown in Scheme 1. The diamine $\mathbf{S 3}$ was obtained by reacting the dibromide $\mathbf{S 2}$ [32] with hexamethylenetetramine and then treating the product with acid and base. The butoxy groups were introduced to positioning the aminomethyl groups. Under pseudo-high dilution conditions, the diamine $\mathbf{S 3}$ and the acid chlorides were added dropwise through a syringe pump to a flask containing $\mathrm{Et}_{3} \mathrm{~N}$ and $\mathrm{CH}_{2} \mathrm{Cl}_{2}$ at room temperature. The tetralactam macrocycles $\mathbf{1}$ and $\mathbf{2}$ were isolated with yields of $22 \%$ and $19 \%$, respectively.

Electrospray ionization (ESI) mass spectra support the isolated products to be the $[2+2]$ macrocycles (see Supporting Information File 1). As shown in Figure 1, the ${ }^{1} \mathrm{H}$ NMR spectra are consistent with high-symmetry structures. There are slight differences in the ${ }^{1} \mathrm{H}$ NMR spectra of the two macrocycles. In particular, the NH protons of 2 (7.51 ppm) are located more downfield than that of $\mathbf{1}(6.08 \mathrm{ppm})$. This should be caused by the intramolecular hydrogen bonds with pyridine nitrogen atoms in $\mathbf{2}$ [35-38]. These hydrogen bonds make macrocycles 2 more pre-organized. In addition, there exist two conformations for both macrocycles 1 and $\mathbf{2}$ because the two 2,3-dibutoxynaphthalene moieties can be aligned either in parallel or antiparallel orientation (Scheme 1). These two conformations have dif- ferent cavities defined by the parallel or antiparallel orientations of the two 2,3-dibutoxynaphthalene moieties; but the same number of peaks in NMR spectra should be observed. Nevertheless, only one set of signals are observed, suggesting that either only one conformation is predominant in solution or the conformational interconversion is fast at the NMR timescale. $\mathrm{H} 3$ is diastereotopic and could be split when the conformational interconversion is slow on the NMR timescale, as observed for oxatub[4] arene [30] and zorb[4] arene [32]. When lowering the temperature to $223 \mathrm{~K}, \mathrm{H} 3$ of $\mathbf{1}$ was split to two peaks while other peaks become broadened (Figure 1b). This suggests that the conformational interconversion is slow at this temperature and only one conformer is predominant in the solution at $298 \mathrm{~K}$. However, the exact conformer cannot be assigned because the two conformers have the same number of peaks. In contrast, H3 of $\mathbf{2}$ are broadened even at room temperature, which may be caused by intramolecular hydrogen bonds, but the conformational interconversion should be fast as well for macrocycle $\mathbf{2}$ at room temperature, which is supported by only one set of sharp signals for the aromatic protons and the non-split and sharp signals of diastereotopic protons at the butyl methylene group next to the oxygen atoms.

A single crystal (Figure 2) of $\mathbf{1}$, which was suitable for X-ray crystallography, was obtained by slow evaporation of its solution in $\mathrm{CH}_{3} \mathrm{CN}$. The crystal structure clearly shows that $\mathbf{1}$ adopts a flattened chair conformation with the two naphthalenes in parallel orientation. Three of the four NH protons are directed into the cavity, and the fourth one flipped outward and forms a hydrogen bond with the oxygen atom of $\mathrm{H}_{2} \mathrm{O}$

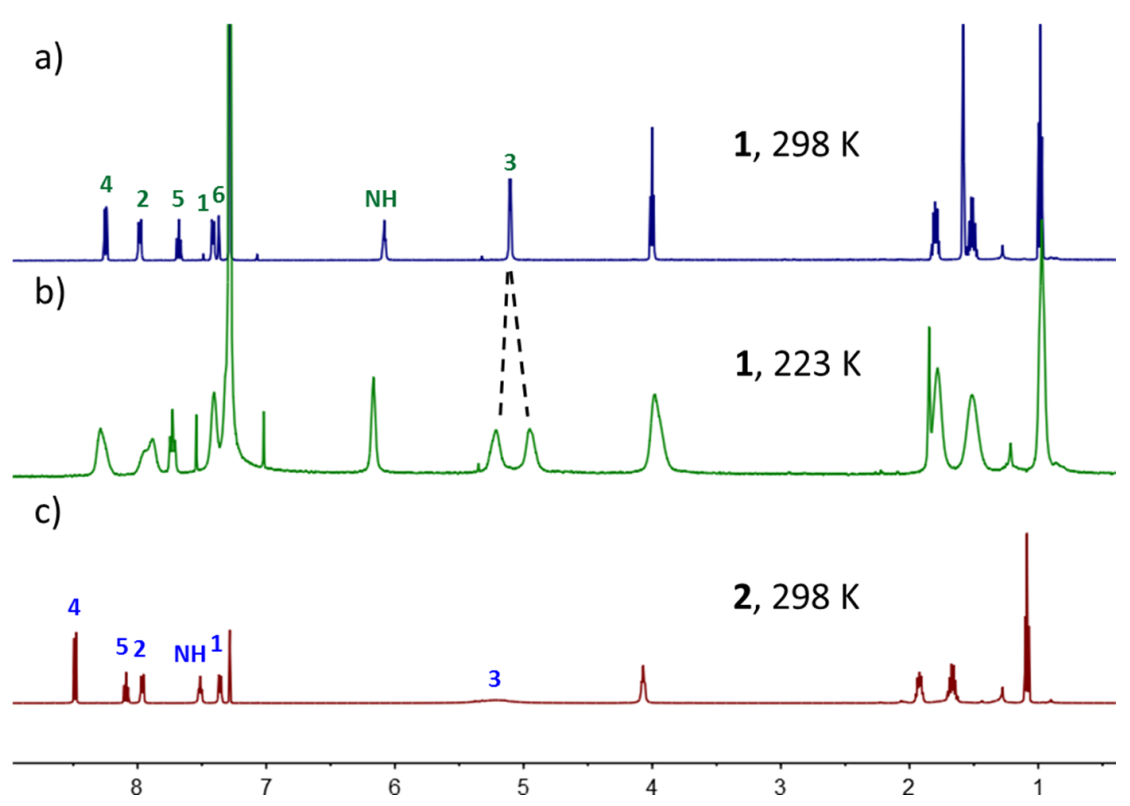

Figure 1: ${ }^{1} \mathrm{H}$ NMR spectra (500 MHz, CDCl3) of a) 1 at $298 \mathrm{~K}$, b) 1 at $223 \mathrm{~K}$, and c) 2 at $298 \mathrm{~K}$. 

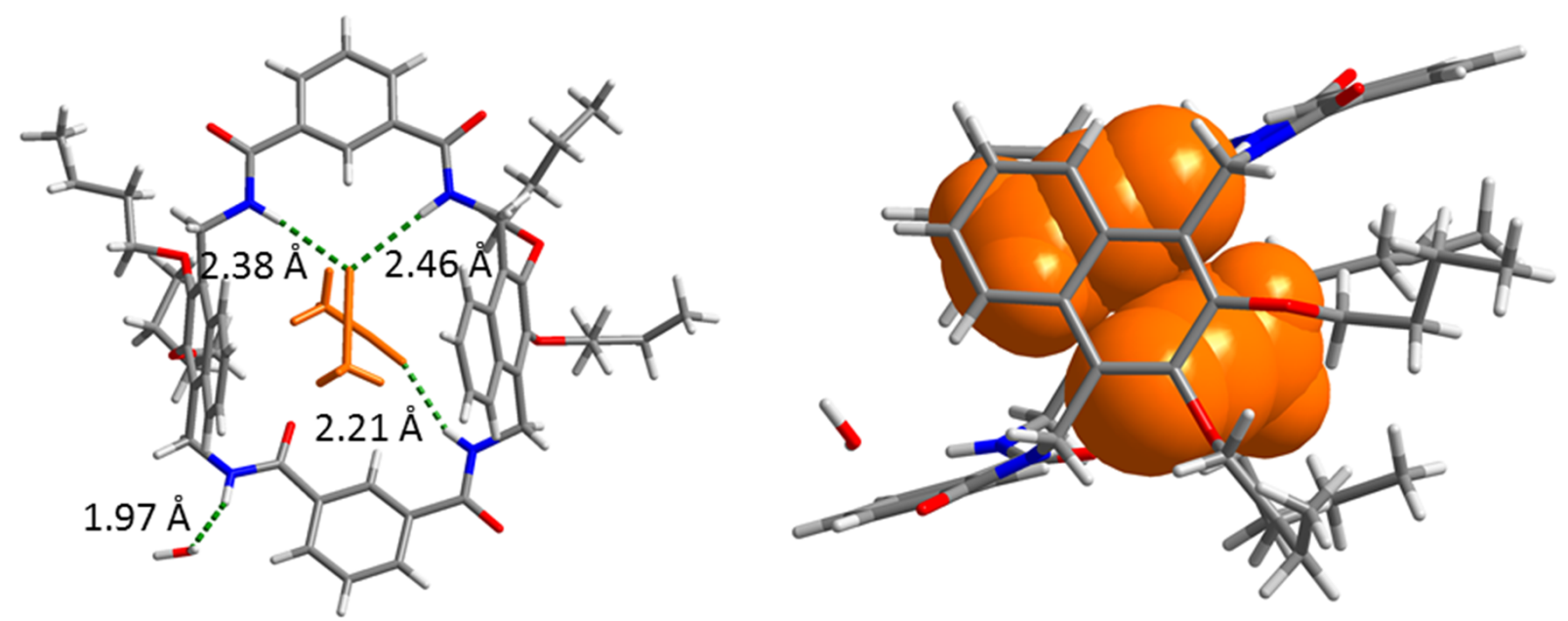

Figure 2: Two different views of the X-ray single crystal structure of 1 obtained from its $\mathrm{CH}_{3} \mathrm{CN}$ solution.

( $\mathrm{H} \cdots \mathrm{O}$ distance: $1.97 \AA$ ). Two $\mathrm{CH}_{3} \mathrm{CN}$ molecules were trapped in the cavities by the amide groups through $\mathrm{N}-\mathrm{H} \cdots \mathrm{N}$ hydrogen bonds ( $\mathrm{H} \cdots \mathrm{N}$ distance: $2.21,2.38$ and $2.46 \AA$ ). $\mathrm{C}-\mathrm{H} \cdots \pi$ interactions ( $\mathrm{H} \cdots \pi$ distance: 2.75 and $2.83 \AA$ ) between the methyl group of $\mathrm{CH}_{3} \mathrm{CN}$ and the naphthalene panels of the host are also detected. This suggests that the 2.3-dibutoxynaphthalene tetralactam macrocycle, just like other tetralactam macrocycles, may use hydrogen bonds to recognize guests with hydrogenbonding acceptors.

Precious metal chloride complexes were found to be complexed by 1 . Obvious chemical shifts in the ${ }^{1} \mathrm{H}$ NMR spectra (Figure 3 ) were observed for $\mathrm{H} 6$ and amide $\mathrm{NH}$ protons when adding one equivalent of the tetrabutylammonium $\left(\mathrm{TBA}^{+}\right)$salt of $\mathrm{AuCl}_{4}{ }^{-}$to the solution of $\mathbf{1}$ in $\mathrm{CDCl}_{3}$. $\mathrm{H} 6$ and $\mathrm{NH}$ in the complex undergo downfield shifts when compared with free 1, suggesting that these protons are involved in hydrogen bonds to the guest.

Job's plot (Figures S1 and S2, Supporting Information File 1) indicates a 1:1 binding stoichiometry, which is further supported by the ESI mass spectrum (Figure 4). The peak at $\mathrm{m} / \mathrm{z}$ 1257.3140 was assigned to $\mathrm{AuCl}_{4}{ }^{-} @ 1$. The experimental isotopic pattern is consistent with the calculated one. In addition, precious metal chloride complexes $\mathrm{PdCl}_{4}{ }^{2-}$ and $\mathrm{PtCl}_{4}{ }^{2-}$

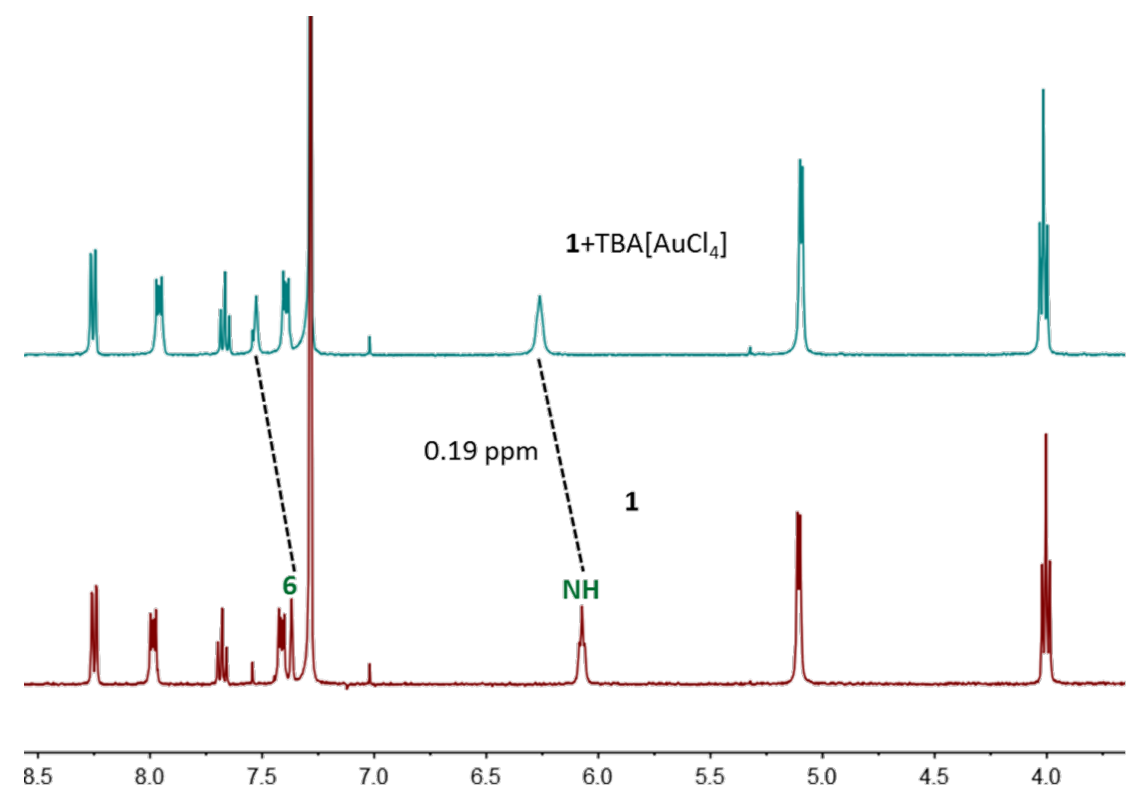

Figure 3: Partial ${ }^{1} \mathrm{H}$ NMR spectra $\left(500 \mathrm{MHz}, \mathrm{CDCl}_{3}, 0.5 \mathrm{mM}, 298 \mathrm{~K}\right)$ of 1 and the equimolar mixture with $\mathrm{TBA}^{\mathrm{AuCl}} \mathrm{Au}_{4}$. 


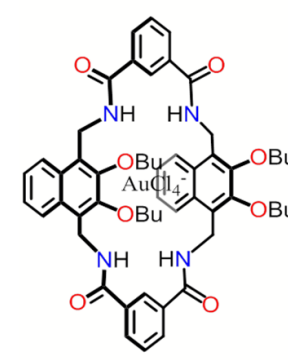

Exact Mass: 1257.3149
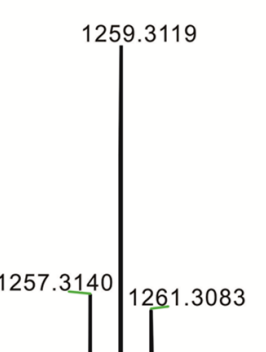
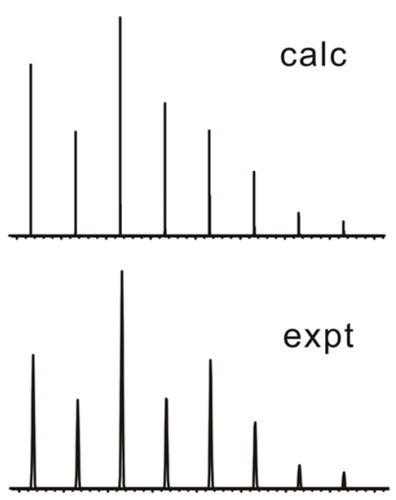

Figure 4: ESI mass spectrum of complex $\mathrm{AuCl}_{4}{ }^{-} @ 1$.

with $\mathrm{TBA}^{+}$as counter ion can be bound by $\mathbf{1}$ as well (Figures S3 and S4, Supporting Information File 1). The binding stoichiometry was also determined to be $1: 1$ by Job's plots (Figures S5-S8, Supporting Information File 1). The chemical shift of $\mathrm{NH}$ protons of $\mathbf{1}$ upon addition of one equivalent of $(\mathrm{TBA})_{2}\left[\mathrm{PtCl}_{4}\right]$ or $(\mathrm{TBA})_{2}\left[\mathrm{PdCl}_{4}\right]$ (Figures $\mathrm{S} 3$ and $\mathrm{S} 4$, Supporting Information File 1) is smaller than that in the presence of one equivalent of TBA[ $\left.\mathrm{AuCl}_{4}\right]$ (Figure 3), although they have rather similar binding affinities. This may be due to a different extent hydrogen bonding is involved in diverse complexes and other non-covalent interactions may contribute more in the cases of $(\mathrm{TBA})_{2}\left[\mathrm{PtCl}_{4}\right]$ or $(\mathrm{TBA})_{2}\left[\mathrm{PdCl}_{4}\right]$.

Binding constants of $\mathbf{1}$ to the precious metal chloride complexes were determined in $\mathrm{CDCl}_{3}$ by ${ }^{1} \mathrm{H}$ NMR titrations (Figures S9-S14, Supporting Information File 1). The data are listed in Table 1. TBA[ $\left.\mathrm{AuCl}_{4}\right]$ shows the highest association constant $\left(K_{\mathrm{a}}\right)$ with a value of $265 \pm 33 \mathrm{M}^{-1}$. The $K_{\mathrm{a}}$ values for $(\mathrm{TBA})_{2}\left[\mathrm{PtCl}_{4}\right]$ and $(\mathrm{TBA})_{2}\left[\mathrm{PdCl}_{4}\right]$ were $189 \pm 36 \mathrm{M}^{-1}$ and $198 \pm 15 \mathrm{M}^{-1}$, respectively. It should be noted that $\mathrm{PdCl}_{4}{ }^{2-}$ is relatively labile at high concentrations and is in equilibrium with the palladate dimer $\left(\mathrm{Pd}_{2} \mathrm{Cl}_{6}{ }^{2-}\right)$ and chloride ions [32,39].
The formation of $\mathrm{Pd}_{2} \mathrm{Cl}_{6}{ }^{2-}$ was supported by an ESI mass spectrum (Figure S15, Supporting Information File 1). Therefore, the association constant for (TBA) $)_{2}\left[\mathrm{PdCl}_{4}\right]$ may, in fact, be caused by the mixture of ( $\mathrm{TBA})_{2}\left[\mathrm{PdCl}_{4}\right], \mathrm{TBACl}$, and $(\mathrm{TBA})_{2}\left[\mathrm{Pd}_{2} \mathrm{Cl}_{6}\right]$. Tetralactam macrocycles are known to bind chloride ions as well $[4,40]$. Indeed, $\mathbf{1}$ is able to bind TBACl with $K_{\mathrm{a}}=90 \pm 13 \mathrm{M}^{-1}$ (Figures S16-S18, Supporting Information File 1). It is interesting that the $\mathrm{NH}$ peak broadens and disappears through the addition of TBACl (Figure S19, Supporting Information File 1) and the underlying reason is still unknown. A similar phenomenon was observed for other tetralactam macrocycles [41].

These binding affinities are lower than those of a positivelycharged macrocycle [42], but are comparable or superior when compared to other tetralactam macrocycles. With respect to the association constants to $\mathrm{TBA}\left[\mathrm{AuCl}_{4}\right]$ and $\mathrm{TBACl}, \mathbf{1}$ is comparable to the tetralactam macrocycles with anthracene as the sidewalls [34], but is significantly weaker than the one with tetramethylphenyl sidewalls [26]. However, $\mathbf{1}\left(189 \mathrm{M}^{-1}\right)$ is superior to these two tetralactam macrocycles (no binding, $20 \mathrm{M}^{-1}$, respectively) [26] in terms of the binding to

Table 1: Association constants $K_{\mathrm{a}}\left(\mathrm{M}^{-1}\right)$ of 1 binding to different guests in $\mathrm{CDCl}_{3}$ at $298 \mathrm{~K}$ determined by ${ }^{1} \mathrm{H}$ NMR titrations

\begin{tabular}{cccc} 
guest & $\left.\mathrm{TBA}_{\mathrm{AuCl}}\right]$ & $\left.(\mathrm{TBA})_{2}[\mathrm{PtCl}]_{4}\right]$ & $(\mathrm{TBA})_{2}\left[\mathrm{PdCl} \mathrm{P}_{4}\right]$ \\
\hline$K_{\mathrm{a}}$ & $265 \pm 33$ & $189 \pm 36$ & $198 \pm 15$
\end{tabular}


$(\mathrm{TBA})_{2}\left[\mathrm{PtCl}_{4}\right]$. This may be due to the existence of two conformations of $\mathbf{1}$, which is conformationally adaptive to the guests. That is, the guest can select the better conformation to maximize the binding affinities, as oxatub[4]arene and zorb[4]arene do $[30,32]$.

In contrast, the addition of these precious metal chloride complexes does not induce any change in the ${ }^{1} \mathrm{H}$ NMR spectrum of 2 (Figure S20, Supporting Information File 1), suggesting 2 not to be a binder of these guests. This is surprising! The only difference between $\mathbf{1}$ and $\mathbf{2}$ is that a pyridine moiety is used in $\mathbf{2}$ in contrast to phenyl group in $\mathbf{1}$. This leads to further hydrogen bonds between the amide $\mathrm{NH}$ protons and the pyridine nitrogen atoms in $\mathbf{2}$, which pre-organizes the cavity for molecular recognition. How would this affect the binding affinity of 2 ? To answer this question, molecular modelling was performed.

Only conformer I of $\mathbf{1}$ was used for the molecular modelling but both conformers are possible. As shown in Figure $5 \mathrm{a}, \mathrm{AuCl}_{4}{ }^{-}$ can be well accommodated in the cavity of $\mathbf{1}$. $\mathrm{AuCl}_{4}{ }^{-}$is sandwiched by the two 2,3-dibutoxynaphthalene moieties, and the electron-poor gold centre of $\mathrm{AuCl}_{4}{ }^{-}$may interact with the electron-rich naphthalenes through electrostatic interactions. In addition, hydrogen bonds are detected between the amide protons and $\mathrm{H} 6$ of $\mathbf{1}$ and the chloride ions of the guest $(\mathrm{H} \cdots \mathrm{Cl}$ distance: 2.48, 2.77 and $2.90 \AA$ ). Consequently, the electrostatic interaction and hydrogen bonds are the main driving forces for the host-guest complex. It is noted that the four amide protons are significantly distorted to accommodate $\mathrm{AuCl}_{4}{ }^{-}$in the cavity of 1. In contrast, $\mathrm{AuCl}_{4}{ }^{-}$cannot be encapsulated in the cavity of 2 (Figure $5 b$ ). Hydrogen bonds between the pyridine moiety and adjacent amides significantly shrink the cavity [43], and thus the cavity cannot be distorted to fit $\mathrm{AuCl}_{4}{ }^{-}$. Otherwise, a high enthalpic penalty would be paid by destroying the intramolecu- lar hydrogen bonds. This may explain why $\mathbf{2}$ is not a binder for these precious metal chloride complexes.

Macrocycle $\mathbf{1}$ is fluorescent because of the 2,3-dibutoxynaphthalene sidewalls and may be used as a fluorescent sensor for these precious metal chloride complexes. The UV-vis absorption spectrum was shown in Figure S21 (Supporting Information File 1), and the absorption maxima are located at $241 \mathrm{~nm}$ and $290 \mathrm{~nm}$. However, the optimal excitation wavelength is at $310 \mathrm{~nm}$ with a quantum yield of $6.6 \%$ in dichloromethane. The emission maximum of $\mathbf{1}$ is located at $350 \mathrm{~nm}$ (Figure S22, Supporting Information File 1). It is known that the binding of metal ions could cause fluorescence quenching through photoinduced electron transfer [44]. Indeed, the fluorescence intensity of $\mathbf{1}$ is quenched gradually upon addition of TBA[AuCl$\left.{ }_{4}\right]$ (Figure 6a). A linear relationship between fluorescent intensity and the concentrations of TBA[AuCl 4$]$ was observed at the concentration range of 20-96 $\mu \mathrm{M}$, giving a detection limit of $0.61 \mu \mathrm{M}$ for TBA[ $\left.\mathrm{AuCl}_{4}\right]$ according to standard methods [45] (Figure 6b). This is similar for $(\mathrm{TBA})_{2}\left[\mathrm{PtCl}_{4}\right]$ within a linear concentration range of $20-970 \mu \mathrm{M}$ and a detection limit of $3.9 \mu \mathrm{M}$ (Figure S23, Supporting Information File 1). For $(\mathrm{TBA})_{2}\left[\mathrm{PdCl}_{4}\right]$, the fluorescence intensity was enhanced at the beginning (Figure S24, Supporting Information File 1), and then quenched with increasing concentrations of (TBA) $)_{2}\left[\mathrm{PdCl}_{4}\right]$ (Figure S25a, Supporting Information File 1). This may be due to the dissociated $\mathrm{TBACl}$ which can induce the fluorescent enhancement of 1 (Figure S26, Supporting Information File 1). A linear concentration range from 60 to $1270 \mu \mathrm{M}$ provides a detection limit of $7.4 \mu \mathrm{M}$ for (TBA) $2\left[\mathrm{PdCl}_{4}\right]$ (Figure S25b, Supporting Information File 1).

\section{Conclusion}

In summary, we reported the synthesis of two new tetralactam macrocycles with 2,3-dibutoxynaphthalenes as the sidewalls.

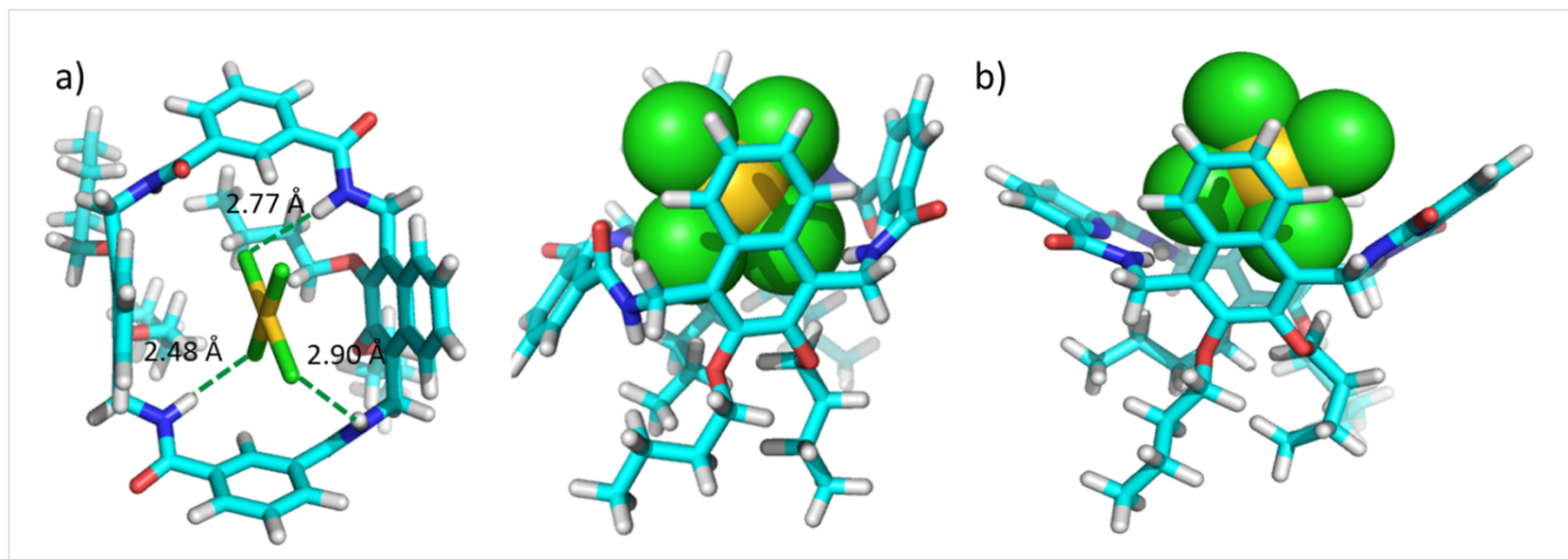

Figure 5: Energy-minimized structure of a) $\mathrm{AuCl}_{4}{ }^{-} @ 1$ and b) $\mathrm{AuCl}_{4}{ }^{-} @ 2$ at the level of theory of PM3 by using Spartan '14 (Wavefunction, Inc.). 

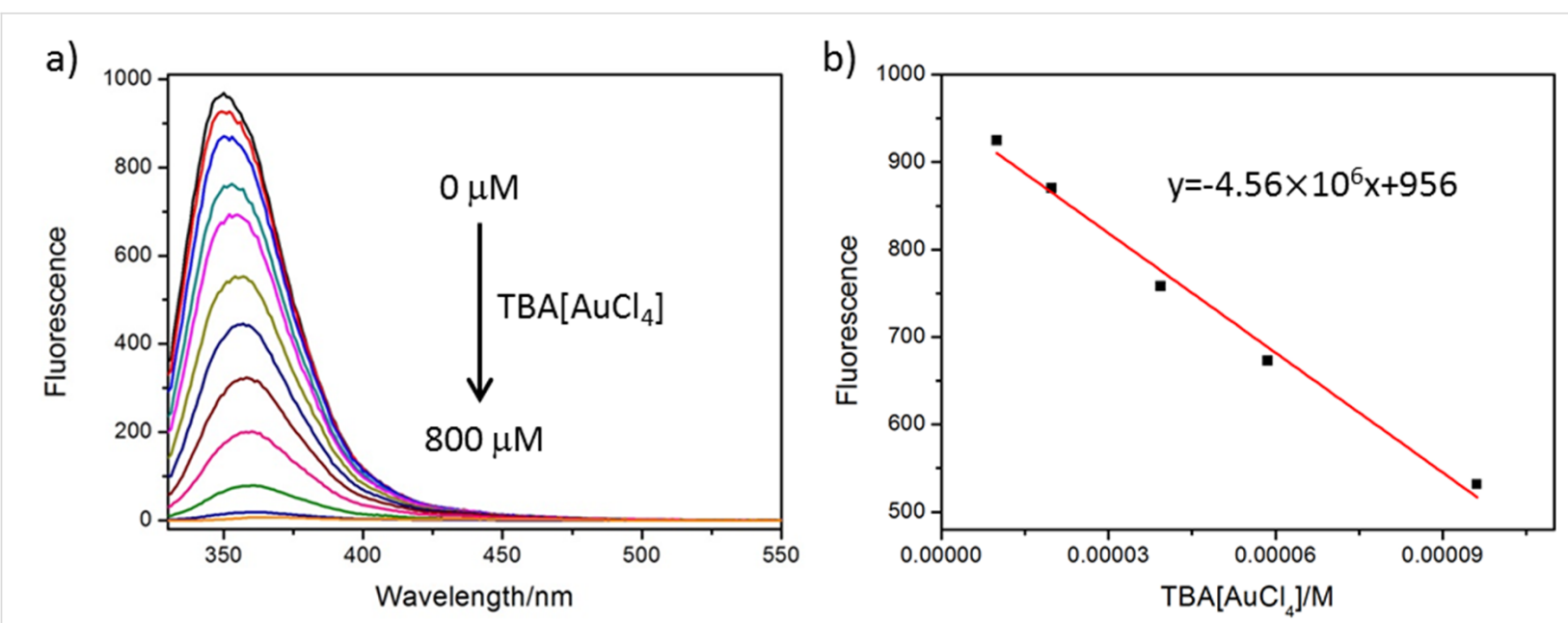

Figure 6: a) Fluorescence emission spectra of $1(20 \mu \mathrm{M})$ upon addition of different amounts of TBA[AuCl 4 ] (concentration range of $0.0-800 \mu \mathrm{M})$ and then recorded in dichloromethane at room temperature $\left(\lambda_{\mathrm{ex}}=310 \mathrm{~nm}\right)$. b) Plot of fluorescence intensity versus $\mathrm{TBA}\left[\mathrm{AuCl} \mathrm{I}_{4}\right]$ concentration $(10-96 \mu \mathrm{M})$.

The macrocycle with isophthalamide as the linkers is able to bind chloride ions and precious metal chloride complexes in nonpolar solvent, while the macrocycle with 2,6-pyridine dicarboxamide bridging units cannot. This may be due to the shrunken cavity caused by intramolecular hydrogen bonds in the latter tetralactam macrocycle. The binding driving forces of the isophthalamide-based macrocycle are mainly from hydrogen bonds and electrostatic interactions between the naphthalenes and the metal centre. Moreover, this naphthalene-based tetralactam macrocycle is generally a good binder for $\mathrm{TBA}\left(\mathrm{AuCl}_{4}\right],(\mathrm{TBA})_{2}\left[\mathrm{PtCl}_{4}\right]$, and $(\mathrm{TBA})_{2}\left[\mathrm{PdCl}_{4}\right]$ complexes, while the tetralactam macrocycles with anthracene and tetramethylphenyl sidewalls [26] shows rather poor binding affinities to $(\mathrm{TBA})_{2}\left[\mathrm{PtCl}_{4}\right]$. This may be due to the possibility of the naphthalene-based macrocycle to adapt its conformation according to the need of the guests to maximize the binding affinities through naphthalene flipping. In addition, this macrocycle is fluorescent and can, in principle, be used as a sensor for the detection of precious metal chloride complexes. These new tetralactam macrocycles with 2,3-dialkoxynaphthalene groups as sidewalls provide a new supplement to the tetralactam macrocycle family and may find further applications in molecular recognition and molecular machines.

\section{Supporting Information}

\section{Supporting Information File 1}

Experimental procedures, NMR and mass spectra, determination of association constants and X-ray single crystal data.

[https://www.beilstein-journals.org/bjoc/content/ supplementary/1860-5397-15-146-S1.pdf]

\section{Acknowledgements}

This research was financially supported by the National Natural Science Foundation of China (Nos. 21772083, 21705075 and 21822104), the SZSTI (Nos. JCYJ20180504165810828 and KQJSCX 20170728162528382) and the Open Fund of State Key Laboratory of Chemo/Biosensing and Chemometrics of Hunan University (2017019). We thank SUSTech-MCPC for instrumental assistance.

\section{ORCID ${ }^{\circledR}$ iDs}

Yi-Kuan Tu - https://orcid.org/0000-0001-7401-2539

\section{References}

1. Schrader, T.; Hamilton, A. D. Functional Synthetic Receptors; Wiley-VCH: Weinheim, Germany, 2005.

2. Leygue, N.; Cazaux, L.; Picard, C.; Tisnes, P. Tetrahedron Lett. 1987, 28, 4049-4052. doi:10.1016/s0040-4039(01)83858-2

3. Hunter, C. A. J. Am. Chem. Soc. 1992, 114, 5303-5311. doi:10.1021/ja00039a047

4. Hübner, G. M.; Gläser, J.; Seel, C.; Vögtle, F. Angew. Chem., Int. Ed. 1999, 38, 383-386. doi:10.1002/(sici)1521-3773(19990201)38:3<383::aid-anie383>3.0.co; 2-h

5. Richter, S.; Poppenberg, J.; Traulsen, C. H.-H.; Darlatt, E.; Sokolowski, A.; Sattler, D.; Unger, W. E. S.; Schalley, C. A. J. Am. Chem. Soc. 2012, 134, 16289-16297. doi:10.1021/ja306212m

6. Szumna, A.; Jurczak, J. Eur. J. Org. Chem. 2001, 4031-4039. doi:10.1002/1099-0690(200111)2001:21<4031::aid-ejoc4031>3.0.co;29

7. Xue, M.; Su, Y.-S.; Chen, C.-F. Chem. - Eur. J. 2010, 16, 8537-8544. doi:10.1002/chem.201000773

8. Wilson, M. R.; Solà, J.; Carlone, A.; Goldup, S. M.; Lebrasseur, N.; Leigh, D. A. Nature 2016, 534, 235-240. doi:10.1038/nature18013

9. Baumes, J. M.; Gassensmith, J. J.; Giblin, J.; Lee, J.-J.; White, A. G.; Culligan, W. J.; Leevy, W. M.; Kuno, M.; Smith, B. D. Nat. Chem. 2010, 2, 1025-1030. doi:10.1038/nchem.871 
10. Ke, C.; Destecroix, H.; Crump, M. P.; Davis, A. P. Nat. Chem. 2012, 4, 718-723. doi:10.1038/nchem.1409

11. Li, D.-H.; Smith, B. D. Beilstein J. Org. Chem. 2019, 15, 1086-1095. doi:10.3762/bjoc.15.105

12. Li, D.-H.; Smith, B. D. J. Org. Chem. 2019, 84, 2808-2816. doi:10.1021/acs.joc.8b03197

13. Martinez-Cuezva, A.; Lopez-Leonardo, C.; Bautista, D.; Alajarin, M.; Berna, J. J. Am. Chem. Soc. 2016, 138, 8726-8729. doi:10.1021/jacs.6b05581

14. Johnston, A. G.; Leigh, D. A.; Pritchard, R. J.; Deegan, M. D. Angew. Chem., Int. Ed. Engl. 1995, 34, 1209-1212. doi:10.1002/anie.199512091

15. Ahmed, R.; Altieri, A.; D'Souza, D. M.; Leigh, D. A.; Mullen, K. M.; Papmeyer, M.; Slawin, A. M. Z.; Wong, J. K. Y.; Woollins, J. D. J. Am. Chem. Soc. 2011, 133, 12304-12310. doi:10.1021/ja2049786

16. Panman, M. R.; van Dijk, C. N.; Huerta-Viga, A.; Sanders, H. J.; Bakker, B. H.; Leigh, D. A.; Brouwer, A. M.; Buma, W. J.; Woutersen, S. Nat. Commun. 2017, 8, 2206. doi:10.1038/s41467-017-02278-6

17. Arunkumar, E.; Forbes, C. C.; Noll, B. C.; Smith, B. D. J. Am. Chem. Soc. 2005, 127, 3288-3289. doi:10.1021/ja042404n

18. Leevy, W. M.; Gammon, S. T.; Jiang, H.; Johnson, J. R.; Maxwell, D. J.; Jackson, E. N.; Marquez, M.; Piwnica-Worms, D.; Smith, B. D. J. Am. Chem. Soc. 2006, 128, 16476-16477. doi:10.1021/ja0665592

19. Liu, W.; Gómez-Durán, C. F. A.; Smith, B. D. J. Am. Chem. Soc. 2017, 139, 6390-6395. doi:10.1021/jacs.7b01628

20. Liu, W.; Johnson, A.; Smith, B. D. J. Am. Chem. Soc. 2018, 140, 3361-3370. doi:10.1021/jacs.7b12991

21. Mandal, P. K.; Kauffmann, B.; Destecroix, H.; Ferrand, Y.; Davis, A. P.; Huc, I. Chem. Commun. 2016, 52, 9355-9358. doi:10.1039/c6cc04466b

22. Ríos, P.; Mooibroek, T. J.; Carter, T. S.; Williams, C.; Wilson, M. R.; Crump, M. P.; Davis, A. P. Chem. Sci. 2017, 8, 4056-4061. doi:10.1039/c6sc05399h

23. Stewart, P.; Renney, C. M.; Mooibroek, T. J.; Ferheen, S.; Davis, A. P. Chem. Commun. 2018, 54, 8649-8652. doi:10.1039/c8cc05074k

24. Ke, H.; Yang, L.-P.; Xie, M.; Chen, Z.; Yao, H.; Jiang, W. Nat. Chem. 2019, 11, 470-477. doi:10.1038/s41557-019-0235-8

25. Jia, F.; Hupatz, H.; Yang, L.-P.; Schröder, H. V.; Li, D.-H.; Xin, S.; Lentz, D.; Witte, F.; Xie, X.; Paulus, B.; Schalley, C. A.; Jiang, W. J. Am. Chem. Soc. 2019, 141, 4468-4473. doi:10.1021/jacs.9b00445

26. Ma, Y.-L.; Ke, H.; Valkonen, A.; Rissanen, K.; Jiang, W. Angew. Chem., Int. Ed. 2018, 57, 709-713. doi:10.1002/anie.201711077

27. Cui, J.-S.; Ba, Q.-K.; Ke, H.; Valkonen, A.; Rissanen, K.; Jiang, W. Angew. Chem., Int. Ed. 2018, 57, 7809-7814. doi:10.1002/anie.201803349

28. Yao, H.; Yang, L.-P.; He, Z.-f.; Li, J.-R.; Jiang, W. Chin. Chem. Lett. 2017, 28, 782-786. doi:10.1016/j.cclet.2016.12.031

29. Huang, G.-B.; Wang, S.-H.; Ke, H.; Yang, L.-P.; Jiang, W. J. Am. Chem. Soc. 2016, 138, 14550-14553. doi:10.1021/jacs.6b09472

30. Jia, F.; He, Z.; Yang, L.-P.; Pan, Z.-S.; Yi, M.; Jiang, R.-W.; Jiang, W. Chem. Sci. 2015, 6, 6731-6738. doi:10.1039/c5sc03251b

31. Li, D.-H.; Yang, L.-P.; Chai, H.; Jia, F.; Ke, H.; Jiang, W. Org. Chem. Front. 2019, 6, 1027-1031. doi:10.1039/c9qo00159j

32. Yang, L.-P.; Jia, F.; Zhou, Q.-H.; Pan, F.; Sun, J.-N.; Rissanen, K.; Chung, L. W.; Jiang, W. Chem. - Eur. J. 2017, 23, 1516-1520. doi:10.1002/chem.201605701
33. Yang, L.-P.; Lu, S.-B.; Valkonen, A.; Pan, F.; Rissanen, K.; Jiang, W. Beilstein J. Org. Chem. 2018, 14, 1570-1577. doi:10.3762/bjoc.14.134 34. Liu, W.; Oliver, A. G.; Smith, B. D. J. Am. Chem. Soc. 2018, 140, 6810-6813. doi:10.1021/jacs.8b04155

35. Hunter, C. A.; Purvis, D. H. Angew. Chem., Int. Ed. Engl. 1992, 31 , 792-795. doi:10.1002/anie.199207921

36. Johnston, A. G.; Leigh, D. A.; Nezhat, L.; Smart, J. P.; Deegan, M. D. Angew. Chem., Int. Ed. Engl. 1995, 34, 1212-1216. doi:10.1002/anie.199512121

37. Affeld, A.; Hübner, G. M.; Seel, C.; Schalley, C. A. Eur. J. Org. Chem. 2001, 2877-2890. doi:10.1002/1099-0690(200108)2001:15<2877::aid-ejoc2877>3.0.co;2$r$

38. Fu, N.; Baumes, J. M.; Arunkumar, E.; Noll, B. C.; Smith, B. D. J. Org. Chem. 2009, 74, 6462-6468. doi:10.1021/jo901298n

39. Lassahn, P.-G.; Lozan, V.; Janiak, C. Dalton Trans. 2003, 927-935. doi:10.1039/b209633a

40. Collins, C. G.; Peck, E. M.; Kramer, P. J.; Smith, B. D. Chem. Sci. 2013, 4, 2557-2563. doi:10.1039/c3sc50535a

41. Gassensmith, J. J.; Matthys, S.; Lee, J.-J.; Wojcik, A.; Kamat, P. V.; Smith, B. D. Chem. - Eur. J. 2010, 16, 2916-2921. doi:10.1002/chem.200902547

42. Dong, C.-C.; Xiang, J.-F.; Xu, L.-J.; Gong, H.-Y. Tetrahedron Lett. 2018, 59, 264-267. doi:10.1016/j.tetlet.2017.12.029

43. Baumes, J. M.; Murgu, I.; Oliver, A.; Smith, B. D. Org. Lett. 2010, 12, 4980-4983. doi:10.1021/ol102132x

44. Huang, H.; Liao, L.; Xu, X.; Zou, M.; Liu, F.; Li, N. Talanta 2013, 117, 152-157. doi:10.1016/j.talanta.2013.08.055

45. MacDougall, D.; Crummett, W. B. Anal. Chem. (Washington, DC, U. S.) 1980, 52, 2242-2249. doi:10.1021/ac50064a004

\section{License and Terms}

This is an Open Access article under the terms of the Creative Commons Attribution License (http://creativecommons.org/licenses/by/4.0). Please note that the reuse, redistribution and reproduction in particular requires that the authors and source are credited.

The license is subject to the Beilstein Journal of Organic Chemistry terms and conditions: (https://www.beilstein-journals.org/bjoc)

The definitive version of this article is the electronic one which can be found at: doi:10.3762/bjoc. 15.146 